\title{
AC 2007-876: UTILIZING INDUSTRIAL COLLABORATION TO INFUSE UNDERGRADUATE RESEARCH INTO THE ENGINEERING TECHNOLOGY CURRICULUM.
}

\section{Jason Durfee, Eastern Washington University}

JASON DURFEE received his BS and MS degrees in Mechanical Engineering from Brigham Young University. He holds a Professional Engineer certification. Prior to teaching at Eastern Washington University he was a military pilot, an engineering instructor at West Point and an airline pilot. His interests include aerospace, aviation, professional ethics and piano technology.

\section{William Loendorf, Eastern Washington University}

WILLIAM R. LOENDORF obtained his B.Sc. in Engineering Science at the University of Wisconsin - Parkside, M.S. in Electrical Engineering at Colorado State University, and M.B.A. at the Lake Forest Graduate School of Management. He holds a Professional Engineer certification and was previously an Engineering Manager at Motorola. His interests include engineering management, real-time embedded systems, and digital signal processing.

\section{Donald Richter, Eastern Washington University}

DONALD C. RICHTER obtained his B. Sc. in Aeronautical and Astronautical Engineering from The Ohio State University, M.S. and Ph.D. in Engineering from the University of Arkansas. He holds a Professional Engineer certification and worked as an Engineer and Engineering Manger in industry for 20 years before teaching. His interests include project management, robotics /automation and air pollution dispersion modeling. 


\title{
Utilizing Industrial Collaboration \\ to Infuse Undergraduate Research \\ into the Engineering Technology Curriculum
}

\begin{abstract}
This paper discusses how the Department of Engineering \& Design (E\&D) at Eastern Washington University (EWU) used real world problems provided by industrial partners to enhance the student's classroom experience using undergraduate research. Last year the Engineering \& Design Department moved into a brand new 93,242 square foot facility. This new facility offered additional lab space along with updated, state-of-the-art equipment. This has positioned the department to work more effectively with members of local industry in collaborative research.
\end{abstract}

This initiative began when members of local industry came to the department with problems that were important for the further development of their products. Faculty members selected students to work with each company to provide this undergraduate research effort. These research projects allowed students to provide solutions, research data, and/or suggest improvements to manufacturing processes. Students provided a valuable service to these community industries both by utilizing university equipment and facilities unavailable at these industries and by providing research and analysis that these companies may not have had time to complete. A faculty member supervised each student to ensure the quality and completion of the research. Students dealt directly with an individual at the company in order to understand the work to be done and how the results were to be presented.

By utilizing real problems from industry the continuation of this program provides a mutual benefit to students, the Department, the University, and local industry. The University is supporting this initiative by providing resources through a Strategic Planning Grant to implement additional projects across the different major programs of the Department (MET, CET, EE, Construction, Design and Manufacturing). This paper will focus on three particular projects undertaken by students during the 2005-'06 academic year. These three projects involved data gathering of new material properties, examinations of dimensional variances in a manufacturing process, and the proof of concept to implement robotic operations to replace manual processes at a local industry.

Introduction

Engineering Technology Students of today need to be better prepared to meet the challenges of the new global economy. To help accomplish this goal students need exposure to real world problems provided by industrial partners. A perfect situation to implement this is through the use of undergraduate research in collaboration with local industry. The infusion of real world problems through undergraduate research helps the students understand the relevance of the 
theory being taught. All too often students fail to see the relevance of the subjects being taught in a traditional lecture or lecture with traditional laboratory. This lack of being able to make the connection from academic classes to the post-graduation expectations of an employer is often given as a reason for poor retention of students. It is imperative to improve retention and help students have a better understanding of what it will be like to be an engineer after graduation. Using undergraduate research projects from industry does some very important things. First it allows the students to explore, apply and stretch their understanding of the theory being taught in the classroom setting. The ability to analyze a problem and conceive solutions is indeed what they will have to do after graduation in the work place environment. Often the research project will require the student to stretch his/her knowledge by digging deeper into a subject than is presented in the classroom. Again this is what is required of the engineer as he/she seeks to solve design problems of today's workplace. Most undergraduate research problems from industry should be worked as a team effort. This allows the students a perfect place to practice the team dynamic skills which are so important in our new global way of doing business. The student has the opportunity to learn, stumble and then succeed in using teamwork skills while being mentored by a faculty member. All of this occurs without the risk of affecting a student's future in a company as it would if this learning took place on the first job after graduation. The use of real world undergraduate research also allows the student to have real world experience before graduation.

Industry forms a closer tie with the university as it then sees the institution as a resource for solving problems it has not the time or maybe the in-house knowledge to tackle. The company also is able to observe and see the value of the graduates from the program and oftentimes makes the decision to hire students from the program. Because of this synergistic relationship industry is very willing to then serve on advisory boards and respond to needs of the department. This often results in additional projects for students from these industrial partnerships and the synergy of this relationship can rapidly expand the number of projects available. This closer relationship and demonstrated community link is very important to the future of any university.

\section{The Case for Undergraduate Research}

The quest for knowledge is the driving force behind undergraduate education no matter what field is being studied. Typically this means a lot of reading from a textbook, completing homework assignments, conducting laboratory experiments, listening to lectures, taking exams, and writing reports. Unfortunately, very little, if any, of this work involves original research. It is usually based on academic work previously done by others. This is especially true in the engineering technology fields where there is so much to learn during that short undergraduate career. However, a new trend is developing that offers the opportunity for undergraduates to add a new dimension to their education by conducting research. "One objective of higher education is to provide students with the ability to make original contributions to Knowledge," (Goodwin \& Hoagland ${ }^{2}, 1999$, p. 2). Now they can apply what they have learned into research efforts as well.

Undergraduate research is of value to the students for many reasons as Malachowski ${ }^{5}$ (1997), Karukstis $^{3}$ (2006) along with Goodwin and Hoagland ${ }^{2}$ (1999) have reported. First, it can affect career decisions leading to graduate school or industry as students get a feel for this type of 
work. Second, research work can remove the monotonous aspects of learning by motivating students to utilize the knowledge they have already learned. Third, research can lead to a sense of confidence, accomplishment, and satisfaction while stimulating the curiosity of the student. Fourth, it can challenge the student to extend their knowledge or apply it in different ways in order to understand some phenomenon. Fifth, it can strengthen communication skills through the writing of professional papers or by the oral presentation of the results of their research to others. Finally, it improves and augments their critical thinking and problem solving skills. In addition, participating along with a faculty mentor in undergraduate research has contributed to increased student retention and achievement during their undergraduate education.

Undergraduate research activities are also an excellent mentoring opportunity for faculty members. "The relationship between the research advisor and the student encompasses much more than simply generating and analyzing experimental data, and may indeed extend well beyond the scope of the research project itself" (Malachowski ${ }^{4}, 1996$, p. 91). In fact, undergraduate research is called a form of apprenticeship by Merkel and Baker ${ }^{6}$ (2002). During this process the mentor takes an active role in training and developing the next generation of engineers, technologists, and scientists. This adds a further dimension to the typical advisor role of academic guidance, career direction, moral support, and encouragement. The advisor now becomes a research manager and mentor as well.

In many cases, this trend has led to the integration of undergraduate research directly into the academic curriculum. After graduation many of the students will be involved in the application, dissemination, and creation of knowledge, or in other words research. As a result it becomes a natural extension of the classical inquiry oriented curriculum to include aspects of research. In fact, "the only difference between research and inquiry based learning is the prior state of knowledge of the broader community. In research it is unknown by all; in inquiry it is only unknown by the learner" (Fortenberry ${ }^{1}, 1998$, p.54). This implies that learning through inquiry is fundamentally equivalent, in the student's perspective, to conduction of research. To the student there is no difference.

\section{Institutional Support}

Unfortunately "many faculty, departments, and institutions struggle with initiating, sustaining, and enhancing their research programs on campus despite the national attention given to the benefits of undergraduate research," (Karukstis ${ }^{3}, 2006$, p. 1744). Luckily this is not the case at Eastern Washington University. In fact, quite the opposite is true. The university actively encourages and promotes undergraduate research. "Creating an environment supportive of undergraduate research requires both its value within the curriculum be understood and that this understanding be made explicit by the academic Dean," (Woodrow \& Fryer ${ }^{8}, 1995$, p. 136). This institutional commitment to undergraduate research is evident by the strong and continued support given by the EWU Vice-Provost for Academic Affairs.

The University's administration even created a Student Research \& Creative Works Office over ten years ago to manage undergraduate research. This office functions as a "catalyst for breaking down the artificial boundaries between learning and discovery and ... it can also be instrumental in increasing undergraduates' awareness of the importance and centrality of research in their 
educational experiences," (Pukkila, Taylor, \& Gray-Little ${ }^{7}, 2001$, p. 177). It was established, in part, because a significant amount of undergraduate research was being done on campus even though it was largely unknown outside the individual departments. One of the major objectives of this office was to celebrate undergraduate research achievements.

To this end, a Student Research \& Creative Works Symposium was established in 1997. This symposium provides an opportunity for students to present their research and creative works in a professional setting. Both oral presentations and poster sessions are held. To begin, abstracts are submitted and reviewed by a faculty committee for acceptance. Then papers are reviewed and recommendations made prior to final submittal. Finally, the program for the event is established and disseminated. This Symposium was a success right from the start and student involvement from all across the campus has continually grown for this event over the years. In mid-May the tenth annual Symposium will be held with hundreds of students expected to contribute and participate.

In order to further promote undergraduate research, a group of six faculty members and two administrators authored a grant proposal to Institutionalize Undergraduate Research Mentoring. Eastern Washington University awarded a Strategic Planning Grant to the proposal with the stated purpose "to increase the opportunities for undergraduates to participate in meaningful research developed and executed under the mentorship of engaged faculty members," (ZeislerVralsted, Keller, \& Kiser" ${ }^{9}$, 2006, p. 1). The grant provided funds for faculty reassigned time, for travel to a Council on Undergraduate Research Workshop, and for technical resources. The objective is to create a University wide infrastructure to encourage and support energetic and vibrant undergraduate research programs while at the same time establishing and nurturing a dynamic research culture.

The faculty members supported by the grant have established an Undergraduate Research Committee to direct, guide, and oversee the execution and realization of its objectives. With the purpose of expanding the program, faculty members from each of the University's departments will be recruited and trained. Each will be charged to lead the effort in their own department by promoting undergraduate research programs and projects. The plan is to interest and involve as many faculty members as possible while gaining support at the grass roots level for undergraduate research programs.

\section{The Engineering \& Design Department Story}

While aspects of undergraduate research had long been a part of the Engineering \& Design Department's curriculum at Eastern Washington University, the move into a new 93,242 squarefoot facility brought greater visibility to the department and what it could do for the community. Three specific examples will be covered in this paper. While each of the projects has its own history, all three were aided by the move to the new building. The new building provided greater lab space, improved equipment and made a statement to the surrounding community that our department was staffed and capable to solve technical problems. In each of the three cases, local manufacturing companies were able to have work done, or processes prototyped that they didn't have the time, facilities or experience to complete. The department reaps the benefit of granting students exposure to actual industry projects while the local manufacturing base benefits by 
knowing that the work will be supervised by a faculty member to ensure completeness and accuracy.

The first project involved some work performed for a local industry located in nearby Spokane that produces refractory materials. Their primary markets for their products are for use in the aluminum industry. There is a division of the company that makes materials for artificial fireplaces that came to our department and wanted to work with a student to gather data on a new high-temperature ceramic material that they were developing. They were able to take advantage of equipment in our materials lab to cure and test samples of this material. A student was selected by the supervising faculty member and the student was put in direct contact with the company engineer. This required the student to learn how to work with a client, find out what exactly they were being asked to do and in what format they wanted the final results presented. The company supplied various samples of different mixes of their new material. The student was required to refer to material testing standards and develop a testing procedure for the samples. The sample testing set up is shown in the following figure.

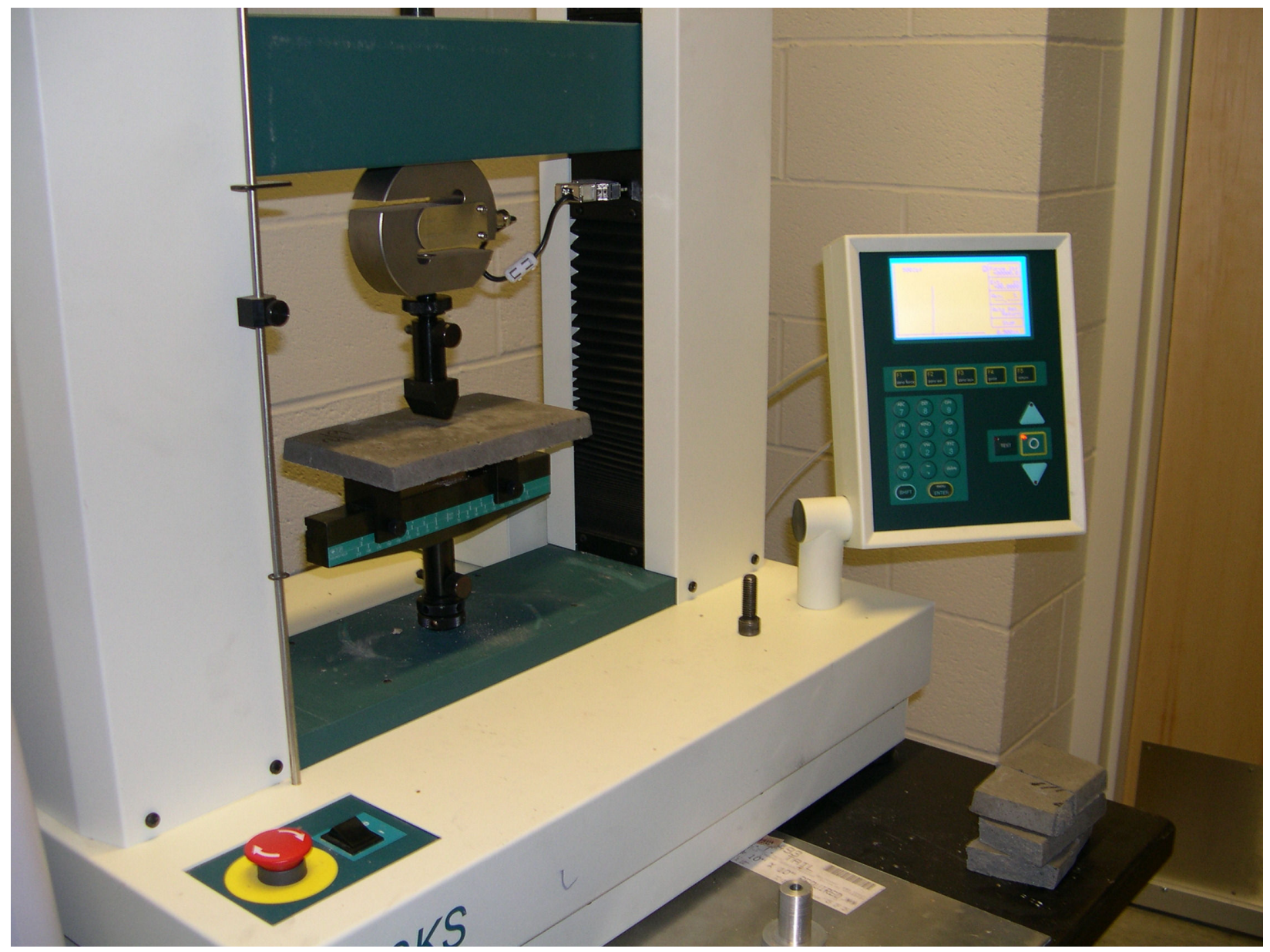

Figure 1, Compression test 
The student was also required to set up a schedule so that the proper samples would be cured in an oven at $1,600^{\circ} \mathrm{F}$ in time for the compression testing to be done at the proper time. The following figure shows the test samples as they are being put into the curing oven.

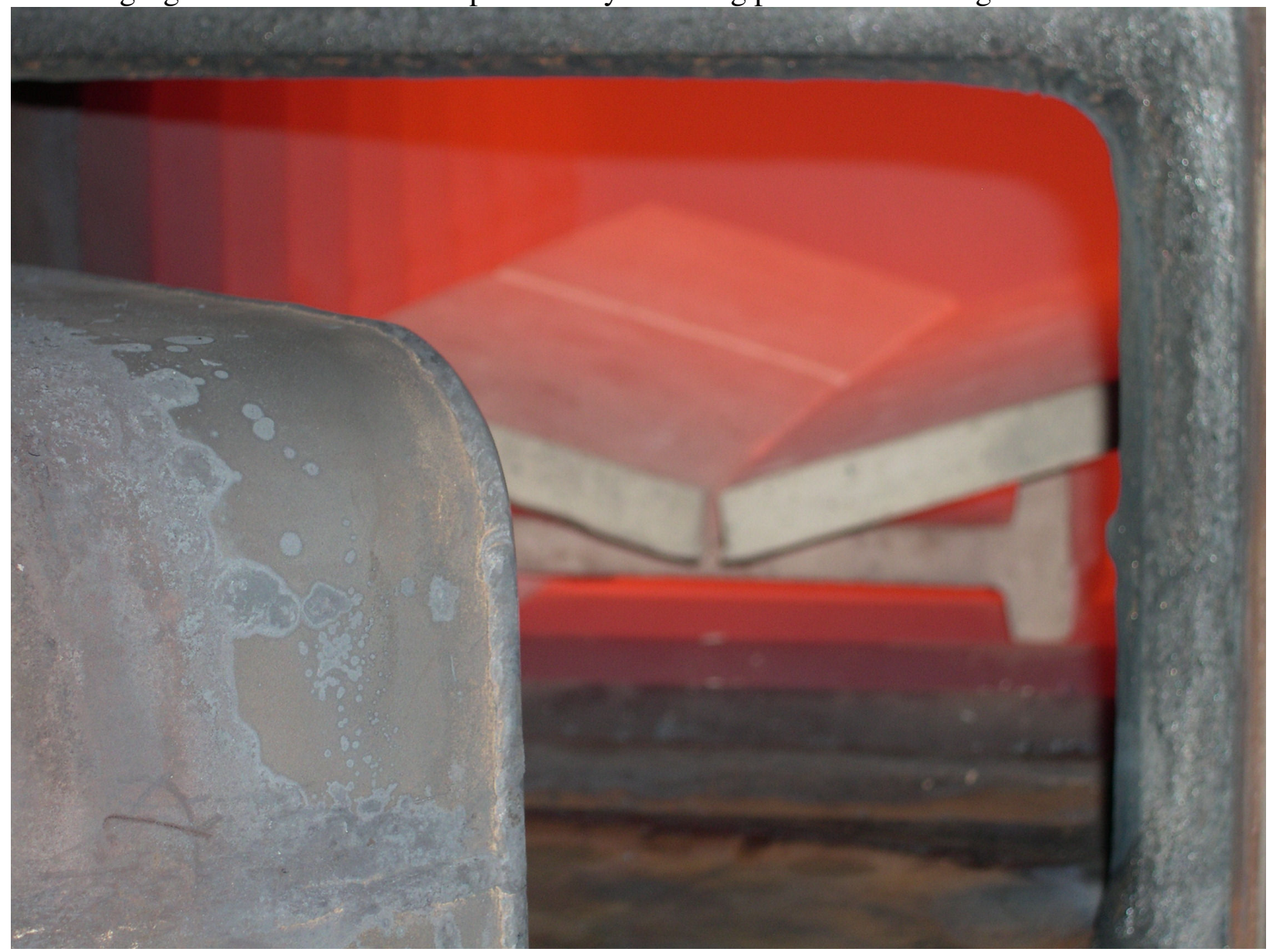

Figure 2, Oven-curing of test samples

The data supplied by the student was utilized by the company in decisions on the use of this new material as well as being presented at a conference by the engineer working with the student. In addition to this expected data, the student was able to provide the company with some information about some tendency towards geometric changes during the curing process as well as some off-gassing of moisture and some volatile products during the curing process. These unexpected issues required the student to work closely with the company engineer, provide pictures of the event and develop a plan for dealing with it.

The second project brought into the department came from a company that makes commercial spun aluminum pans for the commercial baking industry. In this case, the company was having problems with pans it made for the commercial cheesecake industry and was seeking some data to help pinpoint a possible solution. The problems they were having were twofold: first, the pan design had an angled outer edge allowing for ease of stacking for shipping and use during the manufacturing process. However the shape of some of the pans made them difficult to separate after they were stacked without applying very large forces. The second issue that they were 
having with the pans was evidence of a slight dimensional variation when the pans were sent through the anodizing process. A student was selected for this project and was put in contact with the supervising engineer at the company. Working with the company the student was able to come up with a plan of action to provide them with information that would help them in searching for a solution. The student had to design and create two devices to gather the needed information. The first one was a measuring jig that would rigidly hold each pan while dimensional information was obtained from the sample both before and after the anodizing process. The second device that the student had to design and construct was a mounting rig that would allow the student to use the laboratory tensile tester to apply a consistent, repeatable compression force to a stack of pans and then measure the force required to separate the pans. This required some innovation on the part of the student in order to make a device that did not require the alteration of the original pans. Below is a picture of the mounting equipment designed and manufactured by the student and a picture of the setup mounted in the tensile tester during use.

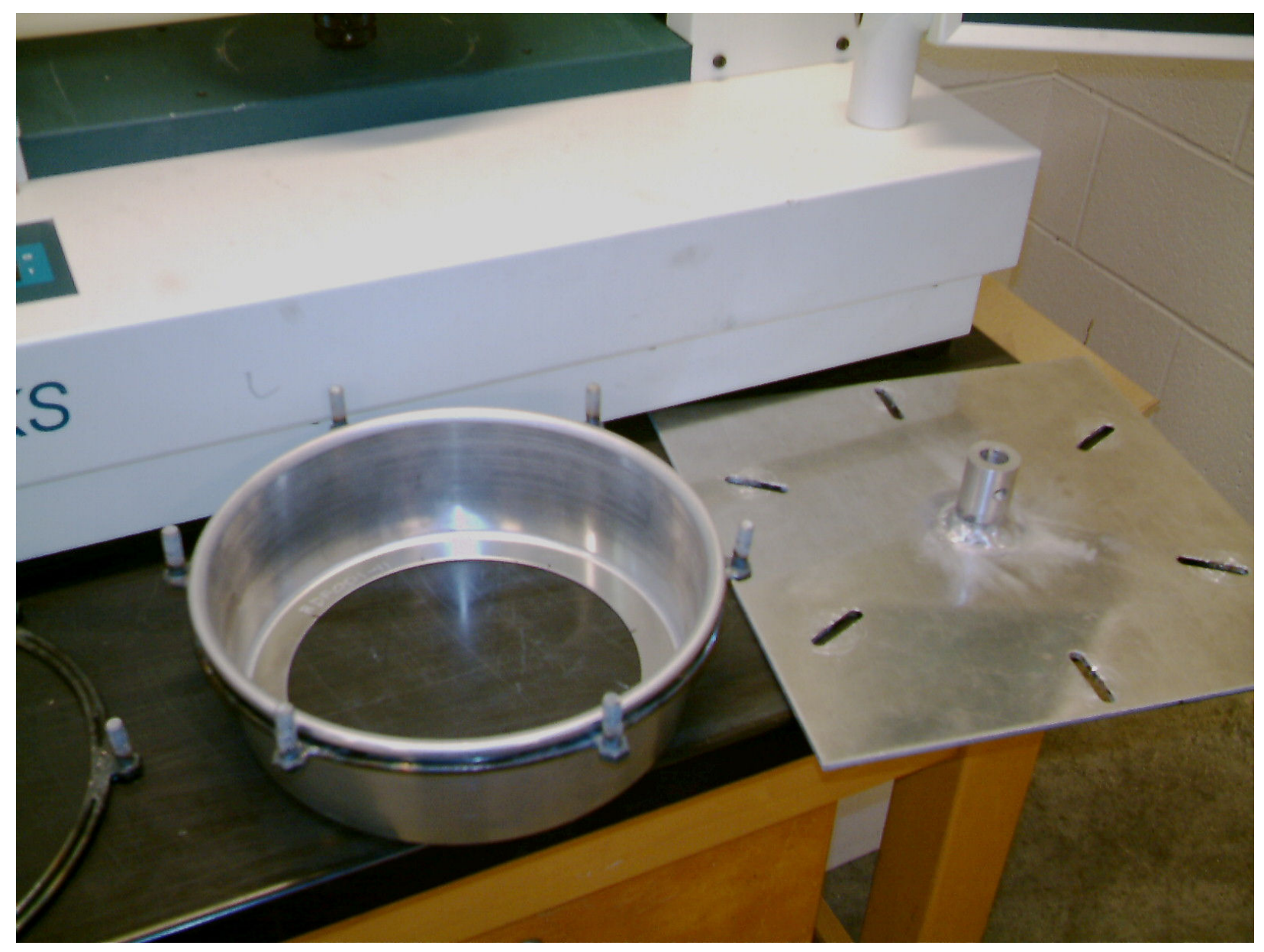

Figure 3, Pan mounting equipment 


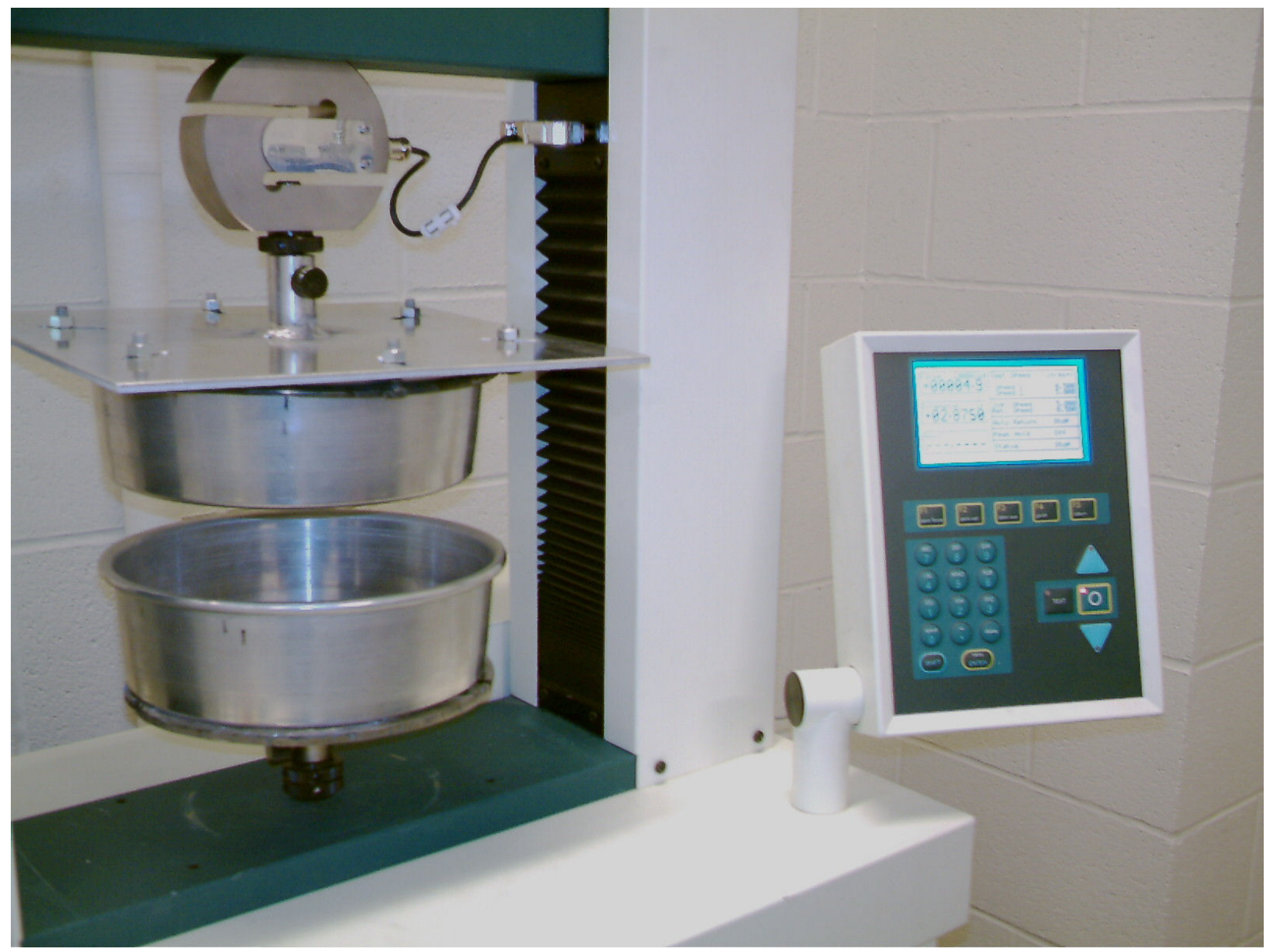

Figure 4, Pans ready for testing

The student was able to obtain the data and provide the information to the company. That data is being analyzed by the company designers to see where changes could be made. As an additional note, the E\&D Department has recently acquired a Coordinate Measuring Machine but this piece of equipment did not arrive in time for this student project. This equipment arrived while the student was finishing his project and he was able to see how a future project requiring geometric measurements will now require much less labor when using this state-of-the-art equipment.

The final of the three student undergraduate research projects to be discussed involved the incorporation of robotics into a manufacturing process. In this case the project was brought to the department by the student. This student had been working as an intern at a local company that manufactures mountain-climbing equipment. While enrolled in a robotics course the student saw the opportunity to incorporate industrial robots into the manufacturing processes he saw during his internship. The student presented the idea to his team and they decided to proceed with the project. This involved developing a robotic process to replace work currently being set-up by hand at the company in a proof of concept research project. They did a mock-up of two punch presses and then did the research to determine if a single robot could tend both punch press machines. The students designed the end-efforts for the robot as well as the work cell configuration. The students then programmed the robot to perform the task tending the machines. 
The robot would take the part to the first press then after the press had done its work transfer the part to the second press and then transfer the finished part to a bin. When the process was scheduled to be presented to the faculty members in the department, the company engineers, managers and owner of the company were invited to the demonstration. The process improvement favorably impressed the company such that they invested in some industrial robots to implement the automated process demonstrated by the student. The student who created the demonstration for them has been offered full-time employment upon graduation.

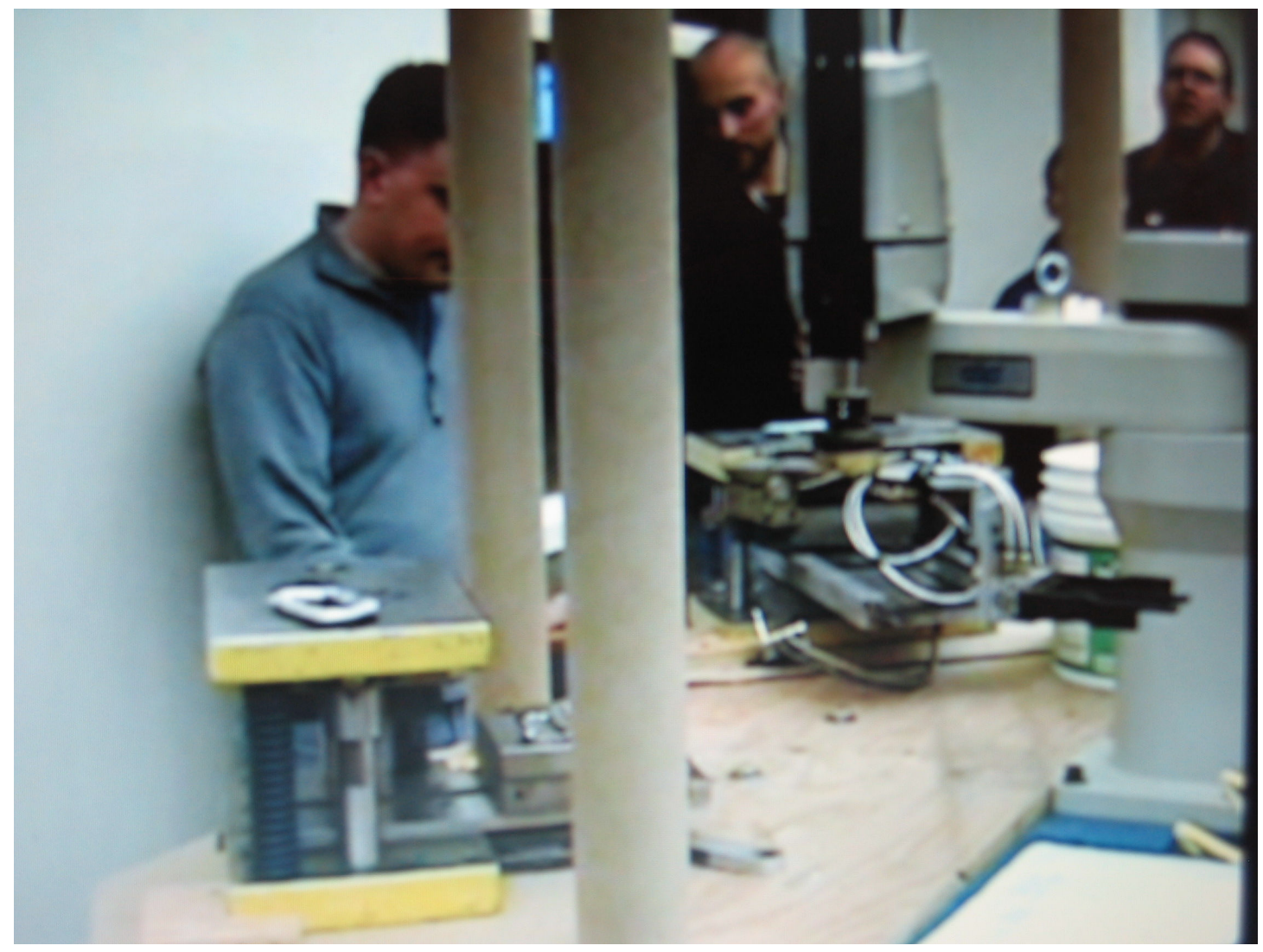

Figure 5 Proof of Concept for loading two Punch Presses

\section{Lessons Learned}

The use of undergraduate research at Eastern Washington University's Engineering \& Design Department has given us the opportunity to grow and learn as a department. It is interesting to note that one of the most important lessons learned was that the student becomes very interested and engaged in this learning experience. This happens in all the areas of their study in the department. The students are able to see the relevance in the course work and often approach their course work with renewed interest. Students not involved directly in the project take interest in following the work and this also has helped them make the connection between the theory and the real world. A striking example of this is the fact that for these three specific projects discussed the students were not compensated for their time. Students were willing to step up and complete the work just for the opportunity of doing actual industrial-related work that would prepare them for their future careers. 
It was observed that regional industry has become more interested in the department and shown a greater willingness to form a partnership with the university. This is a natural outgrowth of industry as it comes to value the department as a resource. These relationships have taken several forms. Industry has been more willing to serve on industrial advisory committees and steering committees to help our program maintain relevance and continue to meet the needs of the regional industries. They have also been very willing to help us obtain grants and donations. It has established connections between industry and the academic role of the university and resulted in visits by local industries to the classroom to discuss their work with students. And of course they have shown more willingness to hire both interns and graduates.

There are some challenges that we have learned to work with as well. The projects from industry must be of the right size and complexity. If the project is too long it cannot be reasonability completed with the student availability. Likewise if the project is too complex for the student's experience level this can also be a problem. Students will get overwhelmed and frustrated in their ability to meet the challenge. Industry needs to understand that these are students and not seasoned professionals and have limited time each week to work on the project. Faculty supervision helps in assuring the research projects are of the right scope and complexity for the student(s) involved. It was also learned to clearly understand the time frame expectations of the industrial partner and make sure that the company has a realistic view of expectations including what the students can and cannot accomplish.

Another lesson learned from this experience is the need to emphasize to students the importance of publicizing their work. This type of work is not really new to the department. Students have been doing projects for industry for years. We have seen an upswing with the move to better facilities and have been able to better market ourselves to the community. What we have learned is that the students who complete the work often fail to get the deserved notice among their peers of what they have done. The previously mentioned university-sponsored, annual Student Research \& Creative Works Symposium is an excellent outlet for the students to show off their work, however none of the students involved in these three projects decided to take part. The department has accepted the challenge to get these students out among their peers to showcase their problem-solving efforts and to take some pride in the work that they have completed including getting their work submitted to this university symposium. Additionally, steps are being taken to institute a seminar-type environment where students that complete undergraduate research will have the opportunity to present their work to the other students within the department.

\section{Conclusions, Reflections, and the Future}

Although having students do work with industry is not a new concept, recognizing the synergism of enhancing student growth and learning as well as advancing the success of local industry is a more recent concept. Eastern Washington University is situated close to many small manufacturing companies that are vital to the economic and technological success of the surrounding area but may not have the necessary resources to research improvements to products and processes. The robotics project is an excellent example of being able to use department facilities to introduce a whole new manufacturing process to a local industry. 
There is little question that these types of projects provide a great opportunity for students. The challenge for the department is to be able to continue to provide these types of opportunities. Having institutional support is vital for this success. The most obvious example of this support for our department is our new facility with increased lab space and equipment. That, alone, has given us much greater visibility within the local community. Additionally, working with local industry so that graduates from the program are employed in the local area is another potential windfall of future projects. Two of the three projects examined in this paper were directly or indirectly influenced by department alumni already employed by these companies. Thus two of these three projects discussed were the fruition of early work by the department's faculty to get graduates hired into local industry.

Although larger projects have been completed within the department, the three projects for industry reported on in this paper were small enough in scope such that a single student performed the necessary work. A mix of projects allowing creativity of individual students as well as others that promote effective teamwork is the ideal that we always seek.

Another item to note is that although these particular projects were accomplished without any outside funds to the students or the department besides the company supplying the materials and some expertise, most projects will likely require some financial commitment from industry. Even so, the benefit that local industry can gain for the small amount they will pay will make the Engineering \& Design Department a very useful resource for local industry.

\section{Bibliography}

1. Fortenberry, N. L. (1998, December). Research \& curriculum. Council on Undergraduate Research Quarterly, 54-61.

2. Goodwin, T. \& Hoagland, K. E. (1999). How to get started in research (2 $2^{\text {nd }}$ ed.). Washington, DC: Council on Undergraduate Research.

3. Karukstis, K. (2006). A council on undergraduate research workshop initiative to establish, enhance, and institutionalize undergraduate research. Journal of Chemical Education, 83, 1744-1745.

4. Malachowski, M. (1996, December). The mentoring role in undergraduate research projects. Council on Undergraduate Research Quarterly, 91-95.

5. Malachowski, M. (1997, June). Not all research is equal: Student-oriented vs. research-oriented approaches to scholarship. Council on Undergraduate Research Quarterly, 182-185.

6. Merkel, C. A. \& Baker, S. M. (2002). How to mentor undergraduate researchers. Washington, DC: Council on Undergraduate Research.

7. Pukkila, P. J., Taylor, D. E., \& Gray-Little, B (2001, June). Why establish an office of undergraduate research? Council on Undergraduate Research Quarterly, 177-179.

8. Woodrow, D. L. \& Fryer, K. H. (1995, March). What might administrators do to foster undergraduate research? Council on Undergraduate Research Quarterly, 136-138.

9. Zeisler-Vralsted, D., Keller, S., \& Kiser, L. (2006). Institutionalizing undergraduate research mentoring. Unpublished manuscript. 